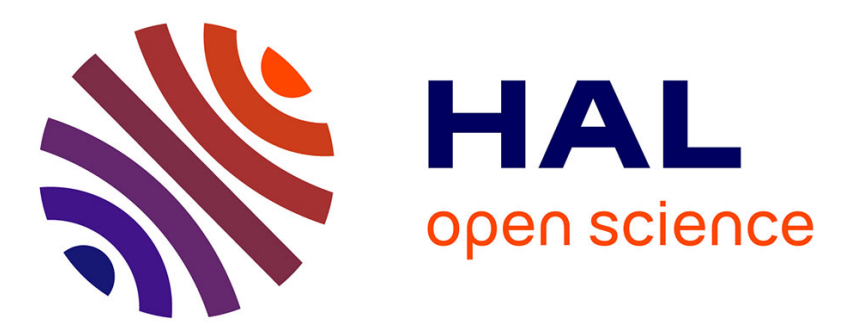

\title{
Nano-sized iron oxides supported on polyester textile to remove fluoroquinolones in hospital wastewater
}

Gnougon Nina Coulibaly, Sami Rtimi, Aymen Amine Assadi, Khalil Hanna

\section{To cite this version:}

Gnougon Nina Coulibaly, Sami Rtimi, Aymen Amine Assadi, Khalil Hanna. Nano-sized iron oxides supported on polyester textile to remove fluoroquinolones in hospital wastewater. Environmental science.Nano, 2020, 7 (7), pp.2156-2165. 10.1039/d0en00261e . hal-02928590

\section{HAL Id: hal-02928590 \\ https://hal.science/hal-02928590}

Submitted on 22 Oct 2020

HAL is a multi-disciplinary open access archive for the deposit and dissemination of scientific research documents, whether they are published or not. The documents may come from teaching and research institutions in France or abroad, or from public or private research centers.
L'archive ouverte pluridisciplinaire HAL, est destinée au dépôt et à la diffusion de documents scientifiques de niveau recherche, publiés ou non, émanant des établissements d'enseignement et de recherche français ou étrangers, des laboratoires publics ou privés. 


\title{
Nano-sized iron oxides supported on polyester textile to remove fluoroquinolones in hospital wastewater
}

\section{Gnougon Nina COULIBALY ${ }^{\mathrm{a}}$, Sami RTIMI ${ }^{\mathrm{b}}$, Aymen Amin ASSADI ${ }^{\mathrm{a}}$, Khalil HANNA ${ }^{\mathrm{a}, \mathrm{c}^{*}}$}

a Univ Rennes, École Nationale Supérieure de Chimie de Rennes, CNRS, ISCR UMR6226, F-35000 Rennes, France.

${ }^{b}$ Ecole Polytechnique Fédérale de Lausanne, EPFL-STI-LTP, Station 12, CH-1015 Lausanne, Switzerland.

${ }^{c}$ Institut Universitaire de France (IUF), MESRI, 1 rue Descartes, 75231 Paris, France.

*Corresponding author: Tel.: +332232380 27; khalil.hanna@ensc-rennes.fr

Revised manuscript to Environmental Science: Nano

May 2020

\begin{abstract}
In this study, we examined the removal kinetics of two fluoroquinolones (FQs), flumequine (FLU) and ciprofloxacin (CIP), in synthetic (SWW) and real hospital wastewaters (RHW) using $\mathrm{FeO}_{\mathrm{x}}$ thin films, peroxymonosulfate (PMS) and visible light. Nano-sized iron oxides (FeOx) supported on polyester textile (PES) were synthesized by a novel high-power impulse magnetron sputtering method (HiPIMS). The $\mathrm{O}_{2} / \mathrm{Ar}$ ratio is an important factor to tune the $\mathrm{Fe}$
\end{abstract}


oxidation, which controls the composition of thin film and thus capability of the resulting $\mathrm{FeO}_{\mathrm{x}}$ for PMS activation. Based on scavenging experiments, sulfate radicals were shown to be predominantly involved in the heterogeneous oxidation reaction. Competitive effects with reactive species could explain the lower degradation rate constants in mixture relative to those in single systems. In contrast to chloride, organic matter, sulfate and phosphates commonly found in RHW, dramatically decreased the removal performance of both target compounds, FLU and CIP. However, increasing PMS concentration to $3 \mathrm{mM}$ improved considerably the degradation and mineralization, even in real wastewaters. The good stability and reusability of $\mathrm{FeOx} / \mathrm{PES}$ material has been confirmed in hospital wastewater over five successive oxidation cycles.

Keywords : iron oxide; supported catalyst; peroxymonosulfate; fluoroquinolones; hospital wastewater.

\section{Table of contents}

Nano-sized iron oxides supported on textile is successfully used for PMS activation and thus flumequine and ciprofloxacin removal in hospital wastewater under visible light.

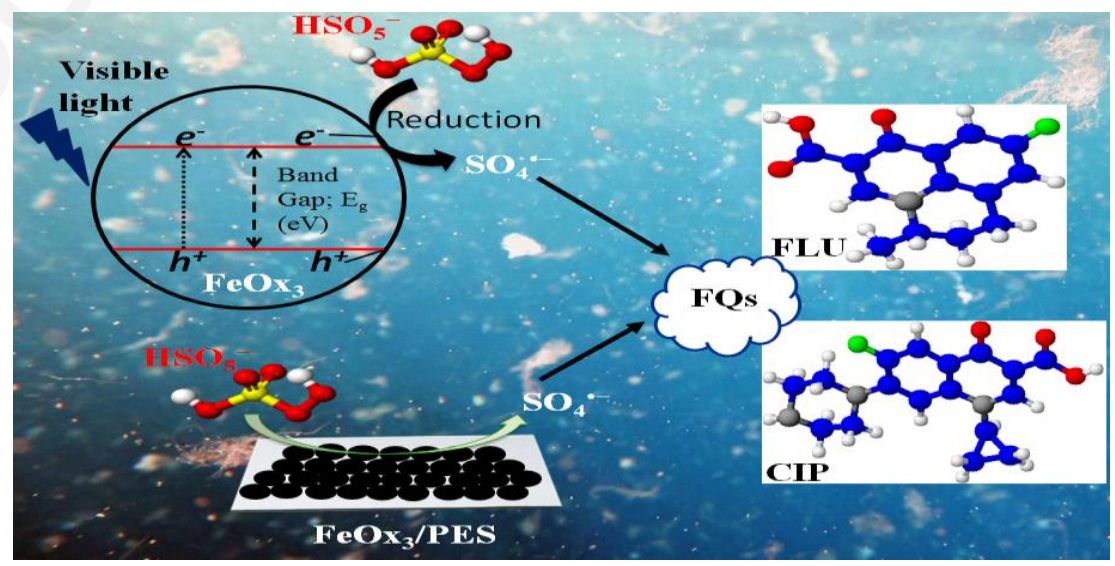




\section{- Introduction}

Fluoroquinolones (FQs) are one of the largest group of antibiotics with an increased use in hospitals, households and veterinary medicine. ${ }^{1,2}$. They were recently classified as a priority risk group because they can cause bacterial resistant. ${ }^{3,4}$ Among FQs, flumequine (FLU) and ciprofloxacin (CIP) represent almost the entire consumption of quinolone antibiotics in the European Union. ${ }^{5}$ FLU and CIP were detected at $6.9 \mu \mathrm{g} \mathrm{g}^{-1}$ in soil ${ }^{6}$ and from 2.5 to $50 \mathrm{ng} \mathrm{\textrm {L } ^ { - 1 }}$ in aquatic environments. ${ }^{7}$ To remove these compounds from contaminated effluents or wastewaters, different strategies have been developed. One of these technologies is advanced oxidation processes (AOPs) which are able to generate reactive oxygen species (ROS) and then achieve degradation of organic compounds. ${ }^{8,9}$ Among AOPs, the photocatalysis process appears as an economic and sustainable technology, particularly when solar light is used as an energy.

When a photon with energy higher than the band gap energy $\left(E_{g}\right)$ of the semiconductor is applied, a photogenerated electron $\left(\mathrm{e}^{-}\right)$in the valence band is excited into the conduction band, leaving a positive hole $\left(\mathrm{h}^{+}\right)$in the valence band. ${ }^{10}$ The photogenerated charge carriers allow the oxidation of organic compounds through the formation of hydroxyl radicals $(\mathrm{OH}) .{ }^{10-12}$ Metal oxides (e.g. Fe-(oxy)hydroxides) can be used as environmentally benign semiconductors, and appear to meet the criteria to promote photo-assisted Fenton reactions. ${ }^{10,13-16}$ It was reported that photogenerated electrons on the surface of semiconductors could activate peroxymonosulfate (PMS), and generate sulfate radicals (2.5$3.1 \mathrm{~V}) .{ }^{17}$ However, little is known about the ability of PMS-activation process to effectively remove contaminants in real wastewaters where target contaminants are found with many 
other substances. In addition, most of published studies used semi-conductor materials in suspension where recovery and/or potential reuse imply costly steps, especially in industrial settings. ${ }^{18-20}$ For this reason, supporting semi-conductors on glass, stainless steel, membrane filters, ceramic or textile has gained great attention, especially in wastewater treatment technologies. ${ }^{18-20}$ Furthermore, the use of visible light-responsive materials may offer cost benefits due to the unlimited sunlight energy. The present work will examine, for the first time, the visible light-responsive photocatalytic activity of supported materials for FQs removal in real hospital wastewaters. In the visible light photocatalysis, the charge transfer rates as well as the hole-electron recombination rate are two critical factors, which could also be affected by the structures, surface properties and morphologies of solids. These key properties can be controlled by the synthesis methods and operational conditions.

In order to develop cost-effective wastewater treatment solutions, we have investigated how the white- light LED could enhance FQs removal in synthetic wastewater (SWW) and in real hospital wastewater (RHW). For this reason, we have deposited nanoscale FeOx on polyester textile (PES) using high-power impulse magnetron sputtering (HiPIMS) under different $\mathrm{Ar} / \mathrm{O}_{2}$ ratios in the sputtering chamber. The spectral absorption and the band gap energies of the resulting oxides have been determined by mean of diffuse reflectance spectroscopy (DRS). The FeOx loading on PES was determined by X-ray fluorescence (XRF) and surface atomic percentages ofFe and $\mathrm{O}$ were determined using X-ray photoelectron spectroscopy (XPS). The nanoparticles distribution and thickness on PES was obtained by Transmission Electron Microscopy (TEM). Finally, the reusability of FeOx/PES system was investigated in hospital wastewater over five oxidation cycles and the influence of wastewater components on the overall performance was discussed. 


\section{- Materials and methods}

\subsection{Materials}

FLU $\left(\mathrm{C}_{14} \mathrm{H}_{12} \mathrm{FNO}_{3} ;>98 \%\right.$ chemical reagent $)$ and $\mathrm{CIP}\left(\mathrm{C}_{17} \mathrm{H}_{18} \mathrm{FN}_{3} \mathrm{O}_{3} ;>98 \%\right)$, PS $\left(\mathrm{Na}_{2} \mathrm{~S}_{2} \mathrm{O}_{8}\right)$, PMS [available as Oxone $\left(\mathrm{KHSO}_{5} \bullet 0.5 \mathrm{KHSO}_{4} \bullet 0.5 \mathrm{~K}_{2} \mathrm{SO}_{4}\right)$ ], isopropanol (i-PrOH, $\left.\mathrm{C}_{3} \mathrm{H}_{8} \mathrm{O}\right)$ and tert-butyl alcohol $\left(\mathrm{t}-\mathrm{BuOH}, \mathrm{C}_{4} \mathrm{H}_{10} \mathrm{O}\right)$, sodium nitrate $\left(\mathrm{NaNO}_{3}\right)$, sodium sulphate $\left(\mathrm{Na}_{2} \mathrm{SO}_{4}\right)$ disodium phosphate $\left(\mathrm{Na}_{2} \mathrm{HPO}_{4}\right)$, citric acid $\left(\mathrm{C}_{6} \mathrm{H}_{8} \mathrm{O}_{7}\right)$, ascorbic acid $\left(\mathrm{C}_{6} \mathrm{H}_{8} \mathrm{O}_{6}\right)$ and sucrose $\left(\mathrm{C}_{12} \mathrm{H}_{22} \mathrm{O}_{11}\right)$ were purchased from the Sigma-Aldrich. Hydrogen peroxide $\left(\mathrm{H}_{2} \mathrm{O}_{2} ; 35 \%\right.$, v/v), $\mathrm{NaOH}$ and $\mathrm{HCl}$ (37\% extra pure) were provided from Acros Organics. The Fe-target in metal form of $5 \mathrm{~cm}$ in diameter $(99.99 \%$ pure) was purchased from K. Lesker Ltd. UK. The standard Leonardite Humic acid (LHA) was provided by International Humic Substances Society (IHSS). Standard solutions were prepared with high-purity water obtained from a Millipore Milli-Q system with 18.2 $\mathrm{M} \Omega \mathrm{cm}$ resistivity. A hospital wastewater sample was provided by the University Hospital Center of Rennes (Rennes city, France) (compositions listed in Table $\mathrm{S} 1, \dagger)$.

\subsection{HiPIMS sputtering of FeOx-PES}

The FeOx coatings were prepared using a High Power Impulse Magnetron Sputtering (HiPIMS). The HiPIMS deposition of metals was carried out in an AJA-vacuum system. The sputtering chamber was evacuated to $10^{-5} \mathrm{~Pa}$ by a turbo-molecular pump. The HiPIMS short pulses avoid a glow-to-arc transition during plasma particle deposition. The sample holder 
was rotating at a speed of $18 \mathrm{rpm}$. The HiPIMS was operated at a frequency of $100 \mathrm{~Hz}$ with a duty cycle of $1 \%$. The magnetic field caused by the magnets behind the Fe-target in the magnetron sputtering (HiPIMS) setting cannot go out due to its para-magnetization. ${ }^{21}$ This hinders the formation of the plasma and thus inhibit the Fe-deposition. In order to fix this problem, the target was machined to let the magnetic field pass through the target. This allows forcing the electrons to follow the normal hopping trajectory along the target as previously reported. ${ }^{21}$ Different FeOx/PES catalysts were synthesized corresponding to the $\% \mathrm{O}_{2}$ in the sputtering chamber as $0,3,5$ and $10 \%$ and are called $\mathrm{FeO}_{0}, \mathrm{FeOx}_{3}, \mathrm{FeO}_{5}$ and $\mathrm{FeO}_{10}$ respectively.

The polyester (PES) used corresponds to the EMPA test cloth sample No 407. It is a polyester Dacron, type 54 spun, plain weave ISO 105-F04 used for color fastness determinations. The thickness of the $\mathrm{FeOx}$ sputtered layers was determined a profilometer (Alphastep500TENCOR, error: $\pm 10 \%$ ). FeOx was sputtered on silica wafers up to 5 minutes in the same conditions as the sputtering on PES fabrics. They were sputtered on $2 \times 2 \mathrm{~cm}$ size of PES.

\subsection{Characterizations of FeOx-PES catalysts}

The FeOx loading was determined by XRF (PANalytical PW2400 spectrometer). The surface atomic percentages of $\mathrm{Fe}$ and $\mathrm{O}$ were then determined with XPS analysis using an AXIS NOVA photoelectron spectrometer (Kratos Analytical, Manchester, UK) equipped with monochromatic AIK $\alpha(\mathrm{h} v=1486.6 \mathrm{eV})$ anode. The proportions of each elements of $\mathrm{FeOx}-$ PES were determined from peak-areas using known sensitivity factors. ${ }^{22}$ The spectral absorption of the deposited FeOx on PES has been carried out using a diffuse reflectance spectroscopy (DRS) in a Perkin Elmer Lambda 900 UV-VIS-NIR spectrometer using bare PES as a standard for baseline. The device is provided for with a PELA-1000 in the 
wavelength range of $200-800 \mathrm{~nm}$. The scan resolution was fixed to $2 \mathrm{~nm}$ steps. The oxides supported on PES with $2 \times 2 \mathrm{~cm}$ size, folded in a few layers, were placed in the working window of the attachment with diffuse reflection. Owing to the large scattering contribution to the reflectance spectra, the rough UV-vis reflectance data cannot be used directly to assess the absorption coefficient of the sputtered samples. ${ }^{23}$ The absorption of the samples was plotted in Kubelka-Munk (KM) arbitrary units versus wavelength.

The sputtered FeOx thin films were imaged using FEI Osiris transmission electron microscope (TEM), operated at $200 \mathrm{kV}$, with spot size of 5, dwell time $50 \mu$ s and real time 600 s. Before imaging, the fibers were embedded in epoxy polymer then cut with ultramicrotome into thin layers with thickness of $\sim 80 \mathrm{~nm}$. These layers were placed on carbon grids then images were acquired.

\subsection{Removal experiments and analytical methods}

A recirculation glass reactor system, described in Fig. S1 (See Electronic supplementary information, $\dagger$ ), was used to investigate the removal performance of supported $\mathrm{FeOx}$ under visible light irradiation. A peristaltic pump (Easy-Load Masterflex Head XX80 ELO 05) was used to circulate the solution into the photoreactor. A light source was a flexible visible light LED strip containing white 10 cold-LEDs. The distance between the LED lamps was fixed at $8 \mathrm{~cm}$ from the solution. The LED lamps emit white light at $455 \mathrm{~nm}$ and further broadband Stokes-shift light emitted at roughly 500-600 nm. The emission spectrum of this white LED lamp was previously reported in Gao et al. (2016). ${ }^{24}$ A digital lux meter was used to measure the average light intensity of LED lamps $\left(0.5 \mathrm{~mW} / \mathrm{cm}^{2}\right)$. The photo-reactor was covered by aluminum foil to prevent the penetration of natural light. All photocatalytic experiments were 
performed at ambient temperature $\left(20 \pm 2^{\circ} \mathrm{C}\right)$ and the $\mathrm{pH}$ was adjusted to $7.0 \pm 0.2$ using 0.1 M HCl or $0.1 \mathrm{M} \mathrm{NaOH}$ solutions. $200 \mathrm{~mL}$ of $5 \mu \mathrm{M}$ of FQs (FLU and CIP) solutions are injected at a constant flow rate $\left(325 \mathrm{~mL} \mathrm{~min}^{-1}\right)$. At each time interval, $1.5 \mathrm{~mL}$ of solution was collected to determine the concentration of each pollutant by high performance liquid chromatography (HPLC). An Alliance UV controller high performance liquid chromatography (HPLC) system equipped with an auto-sampler (Waters 717 plus), a C18 column $(250 \mathrm{~mm} \times 4.6 \mathrm{~mm}$ i.d., $5 \mu \mathrm{m})$ and a UV detector $(246 \mathrm{~nm}$ for FLU, Alliance UV 2489) was used. The mobile phase was a mixture of water/acetonitrile (55:45 v/v for FLU and $85: 15 \mathrm{v} / \mathrm{v}$ for CIP) containing $0.1 \%$ of formic acid. The flow rate of the mobile phase was set at 1 and $0.5 \mathrm{~mL} \mathrm{~min}-1$ in an isocratic mode for FLU and CIP, respectively.

Mineralization in hospital wastewater (or removal of total organic carbon) was examined with a TOC-meter (Shimadzu TOC-VCSH). The iron leaching concentration during reaction was measured using 1,10-phenanthroline method. All experiments were conducted in triplicates and showed a good reproducibility within $5 \%$ of average standard deviation.

\section{- Results and discussion}

\section{- Visible light-assisted oxidation using supported FeOx samples}

The catalytic activity of $\mathrm{FeOx} / \mathrm{PES}$ prepared with different $\mathrm{O}_{2}$ content in the sputtering chamber was investigated at neutral $\mathrm{pH}$ under visible light (Figure 1). Assuming that the visible light promoted oxidation generates reactive species leading to the degradation of the target compound, and the concentration of these species are constant over the reaction time, removal kinetics can be described according to the pseudo-first-order equation (Eq ( 1$)$ ): 
Where $k_{a p p}$, the pseudo-first-order apparent rate constant $\left(\mathrm{h}^{-1}\right)$, is obtained by linear regression of $\ln \left(\mathrm{C}_{\mathrm{t}} / \mathrm{C}_{\mathrm{o}}\right)$ versus time $t$.

It is worth noting that the oxidation kinetics on the $\mathrm{FeOx}_{3}$ cannot be accurately described by simple equations that include classical exponential functions (e.g., pseudo-first order model). Instead, we calculated an initial rate constant over the first stage of reaction (i.e., 10 h) by plotting a linear regression of $-\ln \left(\mathrm{C}_{\mathrm{t}} / \mathrm{C}_{0}\right)$ versus time. This behavior particularly observed for the most reactive system (i.e. $\mathrm{FeO}_{3}$ ) can be ascribed to the complexity of involved reactions including accumulation and competition of reaction products and/or a gradual change of the reactivity of surface sites. For this reason, only a solid line used as a visual guide is shown in Figure 1.

Control tests showed that removal of FLU by adsorption onto FeOx/PES material is negligible. No significant FLU removal was observed with FeOxo (no oxygen added during the sputtering of Fe on PES). However, the preparation of FeOx with a low oxygen content (i.e. $3 \% \mathrm{O}_{2}, \mathrm{FeO}_{3}$ ) during the sputtering led to higher $k_{a p p}, 0.21 \mathrm{~h}^{-1}$ and $97 \%$ of FLU removal. When the oxygen content exceeded 3\%, the FLU kinetic removal dropped down to $0.008 \mathrm{~h}^{-1}$ and $0.004 \mathrm{~h}^{-1}$ for $\mathrm{FeOx}_{5}$ and $\mathrm{FeOx}_{10}$ samples, respectively. This discrepancy in catalytic activity is probably due to difference in type and amount of iron oxides generated on PES surface during the deposition phase. A qualitative analysis of DRS UV-Vis spectral suggested that the lower oxygen content allowed more visible light absorption in $\mathrm{FeOx}$ samples (Figure 2). The band-gaps determination of the sputtered layers in $\mathrm{FeOx}_{3}$ was found to be between 1.9 and $2.2 \mathrm{eV}$ with an absorption edge maximum at around $450 \mathrm{~nm}$ (See Figure 2 for $\mathrm{FeO}_{\mathrm{x} 3}$ ), thereby suggesting a potential photo-activity in the visible range of light. ${ }^{25}$ Due to the low FeOx loading $(0.1 \pm 0.007$ wt.\% PES determined by XRF $)$ and presence of different secondary iron corrosion products of elemental Fe, a quantitative 
determination of the composition of each thin film cannot be obtained. Nevertheless, the $\mathrm{Fe} / \mathrm{O}$ atomic ratio of $\mathrm{FeOx}_{3}$ determined by XPS, after subtracting possible contribution of the polyester substrate in $\mathrm{O}$ atomic percentage, is close to 1 which is in line with a Fe-oxide such as wüstite $(\mathrm{FeO})$.

Even at $0 \% \mathrm{O}_{2}$ (i.e. $\mathrm{O}_{2} / \mathrm{Ar}$ ratio of zero), surface oxidation occurs which can be attributed to the existence of water vapor in the sputtering chamber at the operating conditions, as previously reported. ${ }^{26}$ The great activity of the $\mathrm{FeO}_{\mathrm{x} 3}$ could also be attributed to the homogeneous distribution of $\mathrm{Fe} / \mathrm{FeO}_{\mathrm{x}}$-nanoparticles on the polyester with no apparent cracks (Figure 3a-c). A layer of $\sim 35 \mathrm{~nm}$ thick can be estimated, which is in accordance with the thickness determined by profilometry of $32-42 \mathrm{~nm}$ (Figure $3 \mathrm{~d}$ ).

\subsection{Radical species in the $\mathrm{FeOx}_{3} / \mathrm{PMS} /$ Visible light system}

To test whether other oxidation systems and/or combined processes exhibit high performance of FLU removal as observed for the $\mathrm{FeOx}_{3} / \mathrm{PMS} /$ visible light, removal kinetics were performed with each system separately using the most active $\mathrm{FeOx}$ sample (i.e. $\mathrm{FeOx}_{3}$ ) (Figure 4). As previously reported in literature, ${ }^{27}$ visible light cannot activate PMS, while Feoxides can activate PMS for contaminant degradation ( $k_{a p p}=0.018 \mathrm{~h}^{-1}$ and $55 \%$ removal). FeOx 3 showed $28 \%$ of FLU removal under visible light irradiation, indicating a photocatalytic activity of the supported/sputtered material. Only the combination of PMS, visible light and $\mathrm{FeO}_{3}$ led to complete FLU removal. The addition of other type of oxidants has been also tested using two common oxidants (i.e., PS and $\mathrm{H}_{2} \mathrm{O}_{2}$ ) (Fig. S2, $\dagger$ ). While $\mathrm{H}_{2} \mathrm{O}_{2}$ is completely inefficient, PS exhibits lower efficiency for FLU removal than PMS.

To determine the involved species in the $\mathrm{FeO}_{3} / \mathrm{PMS} /$ visible light system, formation of radical species such as $\mathrm{SO}_{4}{ }^{*}$ and ${ }^{\circ} \mathrm{OH}$ was investigated by assessing the effects of 2-propanol 
and tert-butyl alcohol, because of their different selectivity (i.e., second-order rate constants) with hydroxyl and sulfate radicals ${ }^{28-30}$. Iso-propanol reacts with both $\mathrm{OH}$ and $\mathrm{SO}_{4}(=$ $1.9 \times 10^{9} \mathrm{M}^{1} \mathrm{~s}^{131}$ and $=4-7.4 \times 10^{7} \mathrm{M}^{1} \mathrm{~s}^{132}$ ), while $\mathrm{t}$-butanol can be considered to be more selective toward $\mathrm{OH}\left(=6.0 \times 10^{8} \mathrm{M}^{-1} \mathrm{~s}^{-1} 31\right)$ than $\mathrm{SO}_{4}{ }^{--}\left(=4-8.4 \times 10^{5} \mathrm{M}^{-1} \mathrm{~s}^{-133}\right)$. The percentage of the hydroxyl $\operatorname{radical}\left({ }^{\circ} \mathrm{OH}\right)$ and sulfate radical $\left(\mathrm{SO}_{4}^{{ }^{-}}\right)$reacted with FLU and scavenger can be estimated using the bimolecular rate constants and concentration of each species. According to our calculations (Table $\mathrm{S} 2, \dagger)$, t-Butanol $(5 \mathrm{mM}$ ) is selective for $\mathrm{OH}$ since it will react with more than $98 \%$ of hydroxyl radical. Isopropanol has been used at two high concentrations (i.e. 10 and $20 \mathrm{mM}$ ) to ensure effective and total scavenging of both radical species. Addition of $5 \mathrm{mM}$ of $\mathrm{t}-\mathrm{BuOH}$ resulted in a slight decrease in FLU degradation (Fig. $\mathrm{S} 3, \dagger)$, suggesting that hydroxyl radical is not the main reactive species generated here. The slight inhibition observed here is likely due to the reactivity of t-BuOH with $\mathrm{SO}_{4}{ }^{--}$under our experimental conditions ( Table S2, $\uparrow$ ). Addition of a higher dose of i-PrOH resulted in almost complete inhibition of FLU degradation, confirming the predominance of sulfate radical (Fig. S3, †).

Taken together, these results suggest that the FLU removal in the $\mathrm{FeO}_{3} / \mathrm{PMS} /$ visible light system proceeds via a radical-pathway. Bound FLU reacts with holes $\left(\mathrm{h}^{+}\right)$and PMS with electron, both generated upon irradiation of $\mathrm{FeOx}_{3}$ (band gap $=2.2 \mathrm{eV}$ and with an absorption edge maximum at around $450 \mathrm{~nm}$ ). In addition, PMS can also be activated by Fe species on the surface of $\mathrm{FeOx}_{3}$ and then produce sulfate radicals. These different reactions are given in the ESI (Text S1).

\subsection{Effects of mixture and wastewater components on the removal performance}


To examine the removal ability of the $\mathrm{FeOx}_{3} / \mathrm{PMS} /$ visible light system when target contaminant co-exists with other contaminants, oxidation kinetics were investigated in mixture of FLU and CIP. Higher reactivity of CIP was observed as compared to FLU in single and mixture systems $\left(k_{a p p, C I P}=4.1 \mathrm{~h}^{-1}\right.$ vs $k_{a p p, C I P}=3.1 \mathrm{~h}^{-1}$ in single and mixture system, respectively) (Figure 5). While removal kinetics of FLU showed an initial fast-reaction phase following by a slow stage before an almost total removal at $48 \mathrm{~h}$ of reaction time, the CIP removal kinetic exhibited classical shape, i.e. single-stage leading to faster and total removal of CIP (Figure 5). This is probably due to the strong reactivity of CIP containing cyclopropane and piperazine rings with sulfate radicals, though the second-order rate constants of FLU and CIP with sulfate radicals are quite close $\left(=1.8 \times 10^{9} \mathrm{M}^{-1} \mathrm{~s}^{-1}{ }^{34} \sim=\right.$ $\left.1.2 \times 10^{9} \mathrm{M}^{-1} \mathrm{~s}^{-1},{ }^{35}\right)$. It is reported that the $\mathrm{SO}_{4}{ }^{-}$induces the cleavage of the cyclopropane moiety via loss of one or two $\mathrm{CH}_{2}$ units, whereas the presence of piperazine ring containing two amine- $\mathrm{N}$ is highly reactive with $\mathrm{SO}_{4}{ }^{\bullet-} \cdot 36,37$ This discrepancy in reactivity and/or degradation mechanism may also explain the observed kinetic behavior of CIP versus FLU, and multistage removal kinetics may arise from the competition of mother compound with accumulated byproducts. As expected, CIP and FLU kinetic rate constants decreased 1.3- and 4.2-times, respectively, in the mixture system (Figure 5b), probably due to the competition effects of compounds towards reactive species. It is worth noting that the removal kinetics of CIP or FLU in mixture system exhibited single-stage shape, with a greater reactivity of CIP close to that observed in single system (Figure 5b).

FLU and CIP removal in SWW and RHW systems (compositions listed in Table S1, $\uparrow$ ) were then investigated (Fig HYPERLINK "https://www.sciencedirect.com/science/article/pii/S138589471631899X"ure HYPERLINK "https://www.sciencedirect.com/science/article/pii/S138589471631899X" HYPERLINK "https://www.sciencedirect.com/science/article/pii/S138589471631899X"6). We observed a 
complete inhibition of FLU degradation in both systems, and a dramatic decrease of CIP oxidation in SWW and RHW ( $k_{a p p, C I P}=0.042 \mathrm{~h}^{-1} v s k_{a p p, C I P}=0.048 \mathrm{~h}^{-1}$ in SWW and RHW, respectively). Though the synthetic and real wastewaters have contrasting chemical composition and significant difference in $\mathrm{pH}$ value ( $\underline{\text { Table } \mathrm{S} 1,} \dagger)$, they exhibited similar inhibitive effects whatever the target compound, FLU or CIP (Figure 6).

In order to understand inhibitive effects of wastewater components, FLU removal was investigated in presence of various components as those detected in real wastewaters. Chloride, phosphate, nitrate and sulfate anions are the most inorganic ligands detected in hospital wastewaters, while organic matter and organic ligands (e.g. sucrose and citric acid) were chosen to emulate the organic loading in wastewater. Natural organic matter and organic compounds exhibited significant to complete inhibitive effect on FLU degradation (Figure 7). Despite the ability of citric acid to complex iron and promote Fenton reaction, ${ }^{38}$ significant inhibition was observed. This is probably because of the high ligand loading used in these experiments with respect to the FLU concentration (e.g. molar ratio [Citric acid]/[FLU] $=52$; $[$ Sucrose $] /[\mathrm{FLU}]=58)$. Indeed, high concentrations of ligands lead to strong radical scavenging effects, ${ }^{31}$ thereby offsetting potential enhancing effect from the citrate-iron coordination.

In photo-assisted removal studies, NOM can alter the degradation mechanism through scavenging effects of NOM components and/or light attenuation depending of the total loading. ${ }^{39}$ In the present study, LHA is used as a representative organic matter, which possesses a high oxidation state and high aromaticity, and contains oxygenated polycyclic aromatics and carboxylic compounds which have greater affinity to metal oxides. ${ }^{40-42}$ If the generation of reactive species took place on the $\mathrm{FeO}_{3}$ surface, binding of LHA may poison surface reactivity and scavenge radical species. However, XPS measurements failed to 
accurately assess whether and to which extent organic compounds bind to the oxide layer, probably because of strong contribution of the polyester substrate in carbon percentage. On the other hand, since organic anions can react strongly with radical species, as for instance the reaction of sucrose with hydroxyl radicals, $=2.3 \times 10^{9} \mathrm{M}^{-1} \mathrm{~s}^{-1}$, 31 the strong inhibition observed here is likely due to radical scavenging effects.

The inorganic compounds (i.e., phosphate, nitrate, chloride and sulfate) can react with the sulfate radical, and thus generate novel reactive species with lower or higher reactivity than the sulfate radicals towards target compounds. However, chloride ions exhibited lesser inhibitive effect than phosphate or nitrate, despite its higher reaction constant rate with sulfate radicals $\left(=1.2 \times 10^{6} \mathrm{M}^{-1} \mathrm{~s}^{-1} ;{ }^{32}=2.1 \times 10^{6} \mathrm{M}^{-1} \mathrm{~s}^{-1} ;{ }^{43}=3.0 \times 10^{8} \mathrm{M}^{-1} \mathrm{~s}^{-1} 31,44\right)$. This could be explained if the reaction of chloride ions with sulfate radicals generates other reactive species, which can react effectively with target compound, and thus counterweight the scavenging effect. Previous work showed that increasing in chloride concentration up to $10 \mathrm{mM}$ enhanced CIP degradation in UV-activated PMS system, due to the formation of chlorine active species. ${ }^{45}$ Indeed, PMS can react with $\mathrm{Cl}^{-}$to form $\mathrm{HOCl}$ and $\mathrm{Cl}_{2}$, which exhibit great selectivity towards compounds containing electron-rich organic moieties. ${ }^{46,47}$ In addition, $\mathrm{Cl}^{-}$ may convert $\mathrm{SO}_{4}{ }^{\bullet-}$ into $\mathrm{HO} \cdot$ radicals, as previously reported. ${ }^{48}$ Indeed, fast reaction of $\mathrm{SO}_{4}{ }^{\bullet-}$ with $\mathrm{Cl}^{-}$yields chlorine atoms $\left(\mathrm{Cl}^{\circ}\right)$ as primary products, which in turn initiates a cascade of subsequent reactions depending on $\mathrm{pH}$. At neutral $\mathrm{pH}$ as in the present study, $\mathrm{Cl}^{\bullet}$ mainly reacts with water yielding $\mathrm{HO}^{\bullet}$ radicals. ${ }^{48}$ It is worth noting that the molar ratio of inorganic ligands to the target compound is so high (e.g. around 300 for phosphate and sulfate) that scavenging or inhibitive effects are likely expected in these experiments.

As an attempt to check whether the oxidant dose can be considered as a limiting factor in the degradation of FLU in RHW, the concentration of PMS was increased from $0.5 \mathrm{mM}$ to 2,3 
and $5 \mathrm{mM}$ (Figure 8). The kinetic constant increased from 0 to $0.010 \mathrm{~h}^{-1}, 0.058 \mathrm{~h}^{-1}$ and 0.632 $\mathrm{h}^{-1}$ with increasing PMS dose from 0 to $5 \mathrm{mM}$. Complete removal of FLU was observed with 3 and $5 \mathrm{mM}$, suggesting that increase in PMS concentration would generate sufficient sulfate radicals to achieve FLU removal, even in real wastewater. Furthermore, increasing in PMS concentration form 3 to $5 \mathrm{mM}$ enhanced the mineralization extent from $25 \%$ to $56 \%$, respectively.

The reusability of $\mathrm{FeO}_{3} / \mathrm{PES}$ was then investigated in RHW over five successive runs, with 3 $\mathrm{mM}$ of PMS concentration and at $\mathrm{pH} 7.0 \pm 0.2$ (Figure 9). The kinetic rate constants were then determined for each run, as displayed in Fig. S4, $\uparrow$. While degradation performance is not significantly affected ( $83 \%$ of FLU removal is still observed after 5 cycles), a slight decrease in kinetic rate constant was observed. This could be probably due to the oxidation of $\mathrm{FeOx}$ surfaces over oxidation cycles and/or presence of organic and inorganic compounds on the surface (e.g. organic matter, phosphate, etc.). The $\mathrm{Fe} / \mathrm{O}$ atomic ratio of $\mathrm{FeO}_{3}$ determined by XPS decreased to 0.72 , thereby suggesting oxidation of the nano-oxide layer coating PES. However, the very low iron leaching during oxidation cycles $(<0.02 \mu \mathrm{M})$ suggests a great chemical stability of the $\mathrm{FeOx}_{3}$-PES system.

\section{- Conclusion}

The $\mathrm{PMS} / \mathrm{FeO}_{3}$ can be effectively used for flumequine and ciprofloxacin removal in real wastewaters under low intensity visible light. Using the HiPIMS method, the $\mathrm{O}_{2} / \mathrm{Ar}$ ratio is a key to synthesize a good promoter for PMS activation. The higher degradation rate constant of CIP relative to those of FLU could be explained by the high reactivity of $\mathrm{SO}_{4}{ }^{--}$ radical with cyclopropane ring. Kinetic rate constants were found lower in binary systems 
with respect to those of individual compounds. Moreover, natural organic matter, phosphates and sulfate can considerably inhibit the fluoroquinolone removal in wastewaters, while nitrates and chloride ions exhibited lesser inhibitive effect. In addition, binding of ligands such as phosphates and organic ligands to the oxide surface may alter surface reactivity and thus reduce interactions with contaminants and/or PMS. The sulfate radicals $\left(\mathrm{SO}_{4}{ }^{-}\right)$can be trapped by organic and inorganic ligands found at relatively high loading in wastewater compared to the target contaminant. However, increase in PMS concentration up to $3 \mathrm{mM}$ can generate more radical species and then enhance the removal of target compound, even in real hospital wastewaters. The five successive oxidation runs and the low iron leaching indicated a good stability of catalytic activity of the $\mathrm{FeO}_{3}$-PES system. The results have important implications for cost-effective removal of FQs under visible light irradiation and thus wastewater treatment technologies.

\section{Conflicts of interest}

There are no conflicts to declare.

Acknowledgme nts : This work is part of the Ph.D. thesis of N. Coulibaly supervised by K. Hanna and A. Assadi at the ENSCR School. We gratefully acknowledge the Ministère de l'Enseignement Supérieur et de la Recherche Scientifique of Ivory Coast for the Ph.D. grant of N. Coulibaly. K. Hanna thanks the Institut Universitaire de France for the funding support. S. Rtimi thanks H. Hofmann (EPFL-IMX-LTP) for the financial support.

\section{Footnote}

$\uparrow$ Electronic supplementary information (ESI) associated with this article can be found, in the online version: Additional information regarding composition of SWW and RHW; schematic 
diagram of recirculation glass reactor system; effect of different types of oxidants ; radical scavenging data; removal rate constants in RHW over 5 successive oxidation runs.

\section{Notes and references}

1 A. J. Watkinson, E. J. Murby, D. W. Kolpin and S. D. Costanzo, The occurrence of antibiotics in an urban watershed: From wastewater to drinking water, Science of The Total Environment, 2009, 407, 2711-2723.

2 S. Rodriguez-Mozaz, S. Chamorro, E. Marti, B. Huerta, M. Gros, A. Sànchez-Melsió, C. M. Borrego, D. Barceló and J. L. Balcázar, Occurrence of antibiotics and antibiotic resistance genes in hospital and urban wastewaters and their impact on the receiving river, Water Research, 2015, 69, 234-242.

3 E. Marti, E. Variatza and J. L. Balcazar, The role of aquatic ecosystems as reservoirs of antibiotic resistance, Trends in Microbiology, 2014, 22, 36-41.

4 M. González-Pleiter, S. Gonzalo, I. Rodea-Palomares, F. Leganés, R. Rosal, K. Boltes, E. Marco and F. Fernández-Piñas, Toxicity of five antibiotics and their mixtures towards photosynthetic aquatic organisms: Implications for environmental risk assessment, Water Research, 2013, 47, 2050-2064.

5 N. Janecko, L. Pokludova, J. Blahova, Z. Svobodova and I. Literak, Implications of fluoroquinolone contamination for the aquatic environment-A review, Environmental Toxicology and Chemistry, 2016, 35, 2647-2656.

6 F. Tamtam, F. van Oort, B. Le Bot, T. Dinh, S. Mompelat, M. Chevreuil, I. Lamy and M. Thiry, Assessing the fate of antibiotic contaminants in metal contaminated soils four years after cessation of long-term waste water irrigation, Science of The Total Environment, 2011, 409, 540-547.

7 F. Tamtam, F. Mercier, B. Le Bot, J. Eurin, Q. Tuc Dinh, M. Clément and M. Chevreuil, Occurrence and fate of antibiotics in the Seine River in various hydrological conditions, Science of The Total Environment, 2008, 393, 84-95.

8 F. Ghanbari and M. Moradi, Application of peroxymonosulfate and its activation methods for degradation of environmental organic pollutants: Review, Chemical Engineering Journal, 2017, 310, 41-62.

9 J. Wang and S. Wang, Activation of persulfate (PS) and peroxymonosulfate (PMS) and application for the degradation of emerging contaminants, Chemical Engineering Journal, 2018, 334, 1502-1517.

$10 \mathrm{~W}$. Wu, C. Jiang and V. A. L. Roy, Recent progress in magnetic iron oxide-semiconductor composite nanomaterials as promising photocatalysts, Nanoscale, 2015, 7, 38-58.

11 D. B. Miklos, C. Remy, M. Jekel, K. G. Linden, J. E. Drewes and U. Hübner, Evaluation of advanced oxidation processes for water and wastewater treatment - A critical review, Water Research, 2018, 139, 118-131.

12 M. Pelaez, N. T. Nolan, S. C. Pillai, M. K. Seery, P. Falaras, A. G. Kontos, P. S. M. Dunlop, J. W. J. Hamilton, J. A. Byrne, K. O’Shea, M. H. Entezari and D. D. Dionysiou, A review on the visible light active titanium dioxide photocatalysts for environmental applications, Applied Catalysis B: Environmental, 2012, 125, 331-349.

13 C. Tan, N. Gao, Y. Deng, J. Deng, S. Zhou, J. Li and X. Xin, Radical induced degradation of acetaminophen with $\mathrm{Fe} 3 \mathrm{O} 4$ magnetic nanoparticles as heterogeneous activator of peroxymonosulfate, Journal of Hazardous Materials, 2014, 276, 452-460. 
14 L. Xu and J. Wang, Magnetic Nanoscaled Fe3O4/CeO2 Composite as an Efficient FentonLike Heterogeneous Catalyst for Degradation of 4-Chlorophenol, Environ. Sci. Technol., 2012, 46, 10145-10153.

15 P. Xu, G. M. Zeng, D. L. Huang, C. L. Feng, S. Hu, M. H. Zhao, C. Lai, Z. Wei, C. Huang, G. X. Xie and Z. F. Liu, Use of iron oxide nanomaterials in wastewater treatment: A review, Science of The Total Environment, 2012, 424, 1-10.

$16 \mathrm{M}$. el mehdi Benacherine, N. Debbache, I. Ghoul and Y. Mameri, Heterogeneous photoinduced degradation of amoxicillin by Goethite under artificial and natural irradiation, Journal of Photochemistry and Photobiology A: Chemistry, 2017, 335, 70-77.

$17 \mathrm{~K}$. Zhu, J. Wang, Y. Wang, C. Jin and A. Sundaram Ganeshraja, Visible-light-induced photocatalysis and peroxymonosulfate activation over $\mathrm{ZnFe} 2 \mathrm{O} 4$ fine nanoparticles for degradation of Orange II, Catalysis Science \& Technology, 2016, 6, 2296-2304.

18 D. Kanakaraju, J. Kockler, C. A. Motti, B. D. Glass and M. Oelgemöller, Titanium dioxide/zeolite integrated photocatalytic adsorbents for the degradation of amoxicillin, Applied Catalysis B: Environmental, 2015, 166-167, 45-55.

19 F. Dong, Z. Wang, Y. Li, W.-K. Ho and S. C. Lee, Immobilization of Polymeric g-C $3 \mathrm{~N}_{4}$ on Structured Ceramic Foam for Efficient Visible Light Photocatalytic Air Purification with Real Indoor Illumination, Environmental Science \& Technology, 2014, 48, 1034510353.

20 A. Y. Shan, T. I. Mohd. Ghazi and S. A. Rashid, Immobilisation of titanium dioxide onto supporting materials in heterogeneous photocatalysis: A review, Applied Catalysis A: General, 2010, 389, 1-8.

$21 \mathrm{~S}$. Rtimi and J. Kiwi, Bactericide effects of transparent polyethylene photocatalytic films coated by oxides under visible light, Applied Catalysis B: Environmental, 2017, 213, 6273.

22 D. A. Shirley, High-Resolution X-Ray Photoemission Spectrum of the Valence Bands of Gold, Phys. Rev. B, 1972, 5, 4709-4714.

23 S. Rtimi, S. Giannakis, M. Bensimon, C. Pulgarin, R. Sanjines and J. Kiwi, Supported TiO2 films deposited at different energies: Implications of the surface compactness on the catalytic kinetics., Applied Catalysis B: Environmental, 2016, 191, 42-52.

24 Y. Gao, Z. Zhang, S. Li, J. Liu, L. Yao, Y. Li and H. Zhang, Insights into the mechanism of heterogeneous activation of persulfate with a clay/iron-based catalyst under visible LED light irradiation, Applied Catalysis B: Environmental, 2016, 185, 22-30.

25 R. G. J. Strens and B. J. Wood, Diffuse reflectance spectra and optical properties of some iron and titanium oxides and oxyhydroxides, Mineralogical Magazine, 1979, 43, 347-354.

26 S. Rtimi, O. Baghriche, C. Pulgarin, R. Sanjines and J. Kiwi, Design, testing and characterization of innovative $\mathrm{TiN}-\mathrm{TiO} 2$ surfaces inactivating bacteria under low intensity visible light, RSC Advances, 2012, 2, 8591-8595.

27 C. Li, J. Wu, W. Peng, Z. Fang and J. Liu, Peroxymonosulfate activation for efficient sulfamethoxazole degradation by $\mathrm{Fe} 3 \mathrm{O} 4 / \beta-\mathrm{FeOOH}$ nanocomposites: Coexistence of radical and non-radical reactions, Chemical Engineering Journal, 2019, 356, 904-914.

28 Y. Wu, A. Bianco, M. Brigante, W. Dong, P. de Sainte-Claire, K. Hanna and G. Mailhot, Sulfate Radical Photogeneration Using Fe-EDDS: Influence of Critical Parameters and Naturally Occurring Scavengers, Environ. Sci. Technol., 2015, 49, 14343-14349.

29 E. M. Rodríguez, G. Márquez, M. Tena, P. M. Álvarez and F. J. Beltrán, Determination of main species involved in the first steps of $\mathrm{TiO} 2$ photocatalytic degradation of organics with the use of scavengers: The case of ofloxacin, Applied Catalysis B: Environmental, 2015, 178, 44-53. 
30 M. Kamagate, A. Amin Assadi, T. Kone, L. Coulibaly and K. Hanna, Activation of persulfate by irradiated laterite for removal of fluoroquinolones in multi-component systems, Journal of Hazardous Materials, 2018, 346, 159-166.

31 G. V. Buxton, C. L. Greenstock, W. P. Helman and A. B. Ross, Critical Review of rate constants for reactions of hydrated electrons, hydrogen atoms and hydroxyl radicals $(\cdot \mathrm{OH} / \cdot \mathrm{O}-$ in Aqueous Solution, Journal of Physical and Chemical Reference Data, 1988, 17, 513-886.

32 P. Neta, R. E. Huie and A. B. Ross, Rate Constants for Reactions of Inorganic Radicals in Aqueous Solution, Journal of Physical and Chemical Reference Data, 1988, 17, 10271284.

33 M. Anbar and P. Neta, A compilation of specific bimolecular rate constants for the reactions of hydrated electrons, hydrogen atoms and hydroxyl radicals with inorganic and organic compounds in aqueous solution, The International Journal of Applied Radiation and Isotopes, 1967, 18, 493-523.

34 M. Kamagate, M. Pasturel, M. Brigante and K. Hanna, Mineralization Enhancement of Pharmaceutical Contaminants by Radical-Based Oxidation Promoted by Oxide-Bound Metal Ions, Environ. Sci. Technol., 2020, 54, 476-485.

$35 \mathrm{M}$. Mahdi-Ahmed and S. Chiron, Ciprofloxacin oxidation by UV-C activated peroxymonosulfate in wastewater, Journal of Hazardous Materials, 2014, 265, 41-46.

36 H. Guo, T. Ke, N. Gao, Y. Liu and X. Cheng, Enhanced degradation of aqueous norfloxacin and enrofloxacin by UV-activated persulfate: Kinetics, pathways and deactivation, Chemical Engineering Journal, 2017, 316, 471-480.

37C. Jiang, Y. Ji, Y. Shi, J. Chen and T. Cai, Sulfate radical-based oxidation of fluoroquinolone antibiotics: Kinetics, mechanisms and effects of natural water matrices, Water Research, 2016, 106, 507-517.

38 M. R. A. Silva, A. G. Trovó and R. F. P. Nogueira, Degradation of the herbicide tebuthiuron using solar photo-Fenton process and ferric citrate complex at circumneutral pH, Journal of Photochemistry and Photobiology A: Chemistry, 2007, 191, 187-192.

39 A. R. Lado Ribeiro, N. F. F. Moreira, G. Li Puma and A. M. T. Silva, Impact of water matrix on the removal of micropollutants by advanced oxidation technologies, Chemical Engineering Journal, 2019, 363, 155-173.

$40 \mathrm{H}$. Kerndorff and M. Schnitzer, Sorption of metals on humic acid, Geochimica et Cosmochimica Acta, 1980, 44, 1701-1708.

41 K. Yang, D. Lin and B. Xing, Interactions of Humic Acid with Nanosized Inorganic Oxides, Langmuir, 2009, 25, 3571-3576.

42 S. Jayalath, H. Wu, S. C. Larsen and V. H. Grassian, Surface Adsorption of Suwannee River Humic Acid on TiO2 Nanoparticles: A Study of pH and Particle Size, Langmuir, 2018, 34, 3136-3145.

43 H. Gao, J. Chen, Y. Zhang and X. Zhou, Sulfate radicals induced degradation of Triclosan in thermally activated persulfate system, Chemical Engineering Journal, 2016, 306, 522530.

44 Y. Yang, J. J. Pignatello, J. Ma and W. A. Mitch, Comparison of Halide Impacts on the Efficiency of Contaminant Degradation by Sulfate and Hydroxyl Radical-Based Advanced Oxidation Processes (AOPs), Environ. Sci. Technol., 2014, 48, 2344-2351.

45 X. Ao, W. Liu, W. Sun, M. Cai, Z. Ye, C. Yang, Z. Lu and C. Li, Medium pressure UVactivated peroxymonosulfate for ciprofloxacin degradation: Kinetics, mechanism, and genotoxicity, Chemical Engineering Journal, 2018, 345, 87-97.

46 C. Sichel, C. Garcia and K. Andre, Feasibility studies: UV/chlorine advanced oxidation treatment for the removal of emerging contaminants, Water Research, 2011, 45, 63716380 . 
47 E. A. Serna-Galvis, S. D. Jojoa-Sierra, K. E. Berrio-Perlaza, F. Ferraro and R. A. TorresPalma, Structure-reactivity relationship in the degradation of three representative fluoroquinolone antibiotics in water by electrogenerated active chlorine, Chemical Engineering Journal, 2017, 315, 552-561.

48 H. V. Lutze, N. Kerlin and T. C. Schmidt, Sulfate radical-based water treatment in presence of chloride: Formation of chlorate, inter-conversion of sulfate radicals into hydroxyl radicals and influence of bicarbonate, Water Research, 2015, 72, 349-360.

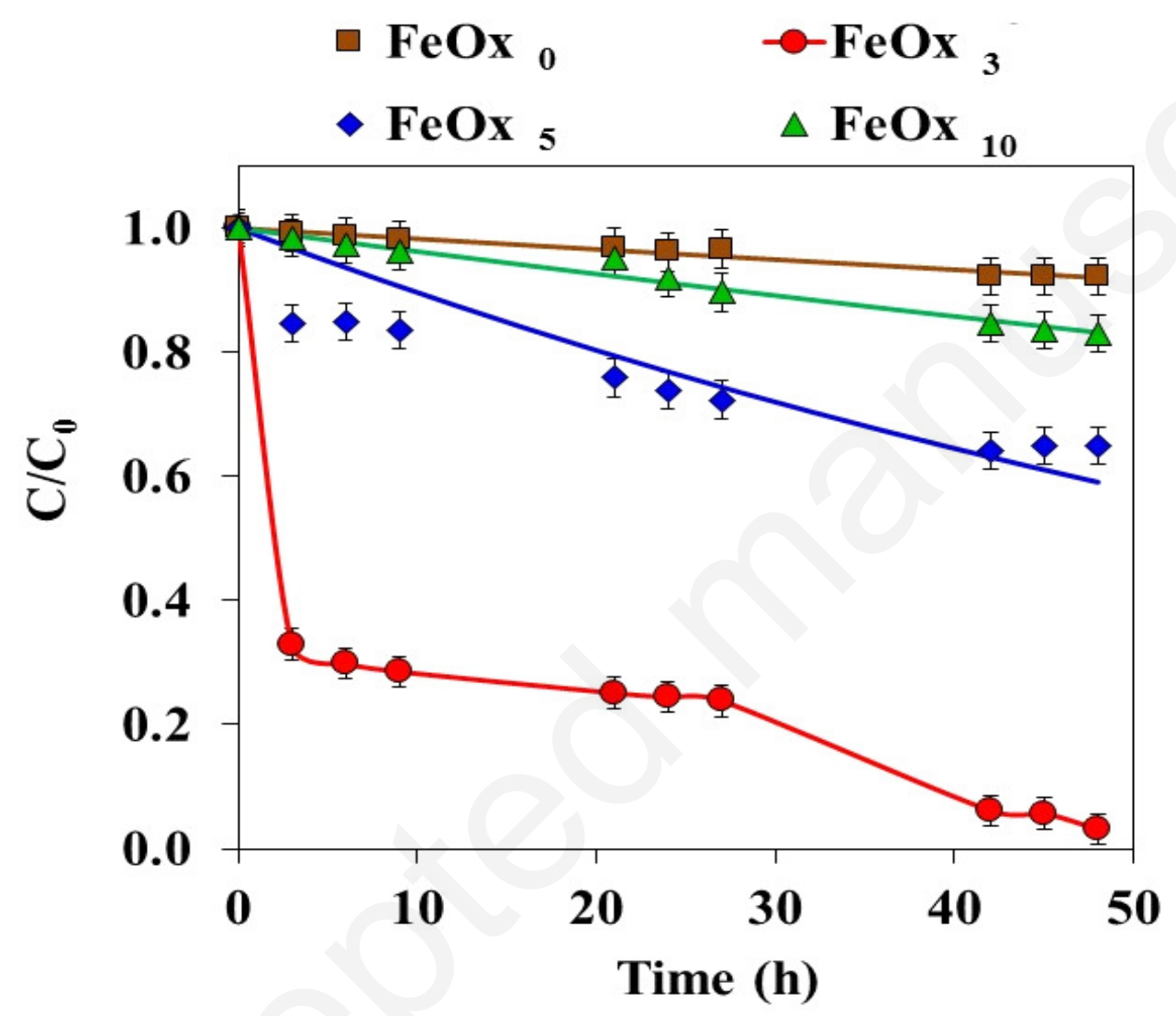

Figure 1. Removal of FLU with different $\mathrm{FeOx}$, synthetized under different $\mathrm{O}_{2}$ level conditions. Experimental conditions: $[\mathrm{FLU}]_{0}=5 \mu \mathrm{M},[\mathrm{PMS}]_{0}=0.5 \mathrm{mM},[\mathrm{FeOx}]=0.26 \mathrm{~g} \mathrm{~m}^{-2}$ on PES, visible light irradiation $(\lambda>420 \mathrm{~nm})$, reaction time $=48 \mathrm{~h}, \mathrm{pH} 0=7.0 \pm 0.2, \mathrm{~V}=200$ $\mathrm{mL}$, recirculation flowrate $=325 \mathrm{~mL} \mathrm{~min}^{-1}$. Abbreviations: FLU $=$ flumequine, PMS $=$ peroxymonosulfate, $\mathrm{FeOx}_{0}, \mathrm{FeO}_{3}, \mathrm{FeO}_{5}$ and $\mathrm{FeO}_{10}$ are synthetized samples, corresponding to $0,3,5$ and $10 \%$ as $\% \mathrm{O}_{2}$ in the sputtering chamber, respectively. For $\mathrm{FeOx}_{3}$, the solid line is only a visual guide. 


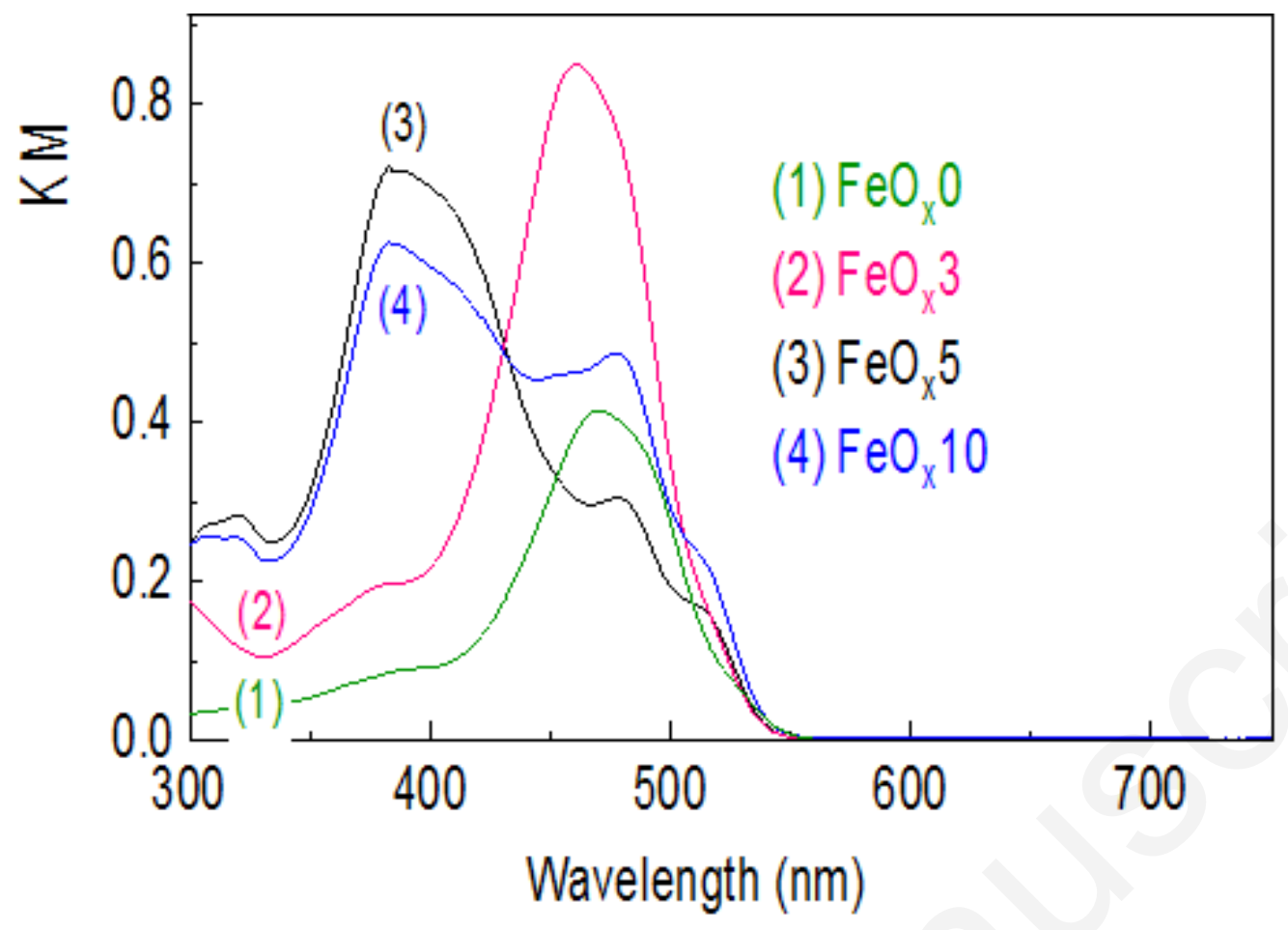

Figure 2. Diffuse reflectance spectroscopy (DRS) of FeOx sputtered samples under different oxygen content. $\mathrm{FeO}_{0}, \mathrm{FeOx}_{3}, \mathrm{FeOx}_{5}$ and $\mathrm{FeO}_{10}$ are synthetized samples, corresponding to $0,3,5$ and $10 \%$ as $\% \mathrm{O}_{2}$ in the sputtering chamber, respectively. 
a)

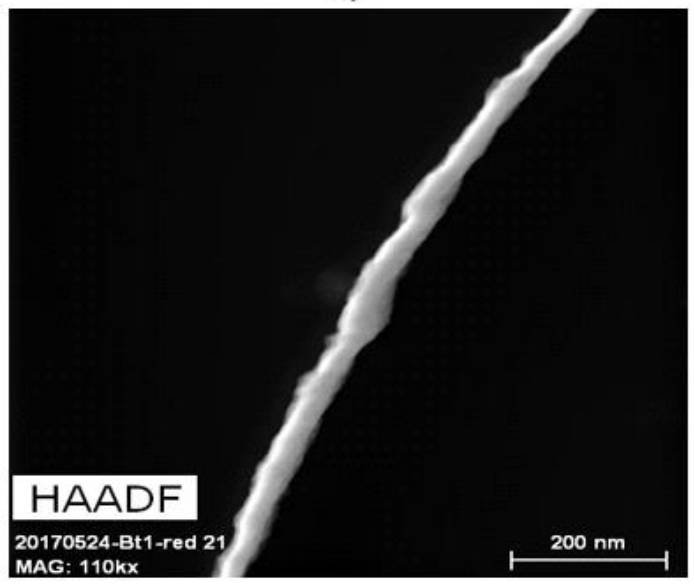

c)

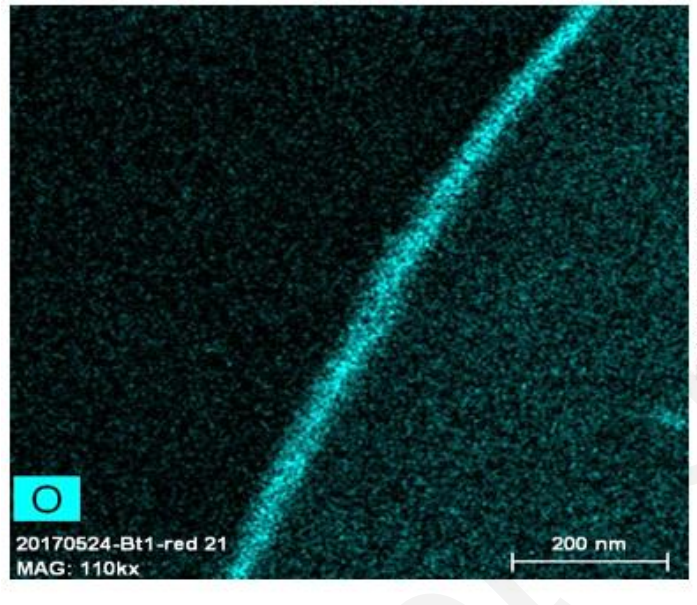

b)

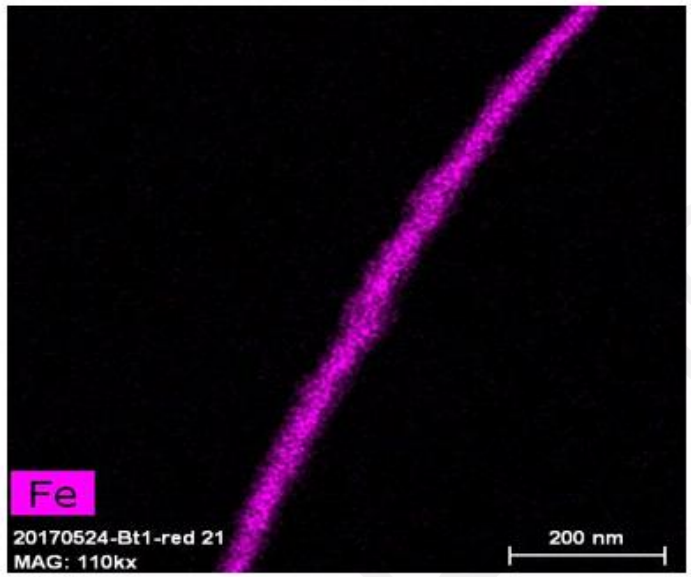

d)

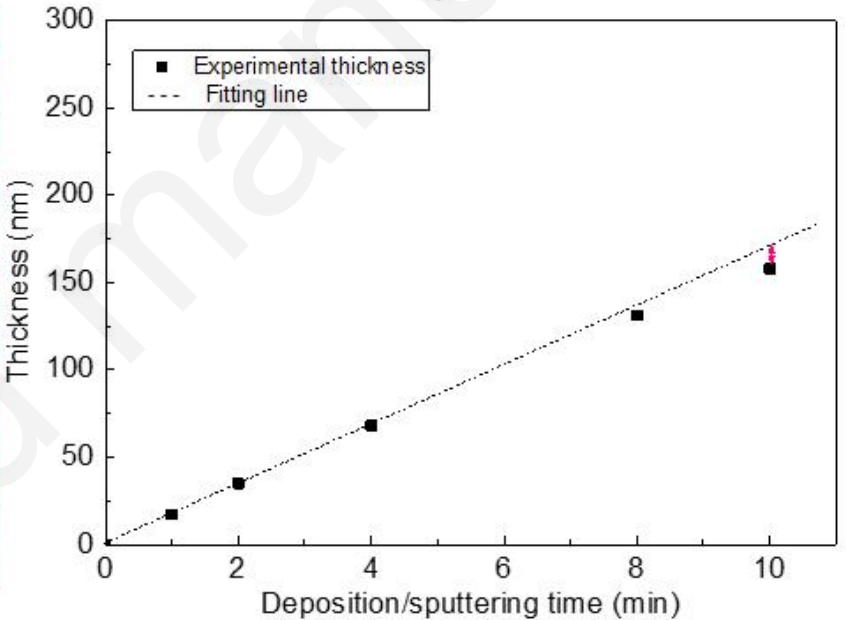

Figure 3a-c. Transmission Electron Microscopy (TEM) analysis of the HiPIMS sputtered fabrics for 2 min and the Fe and $\mathrm{O}$ mapping. Figure 3d. Thickness calibration of the HiPIMS sputtered thin films. 


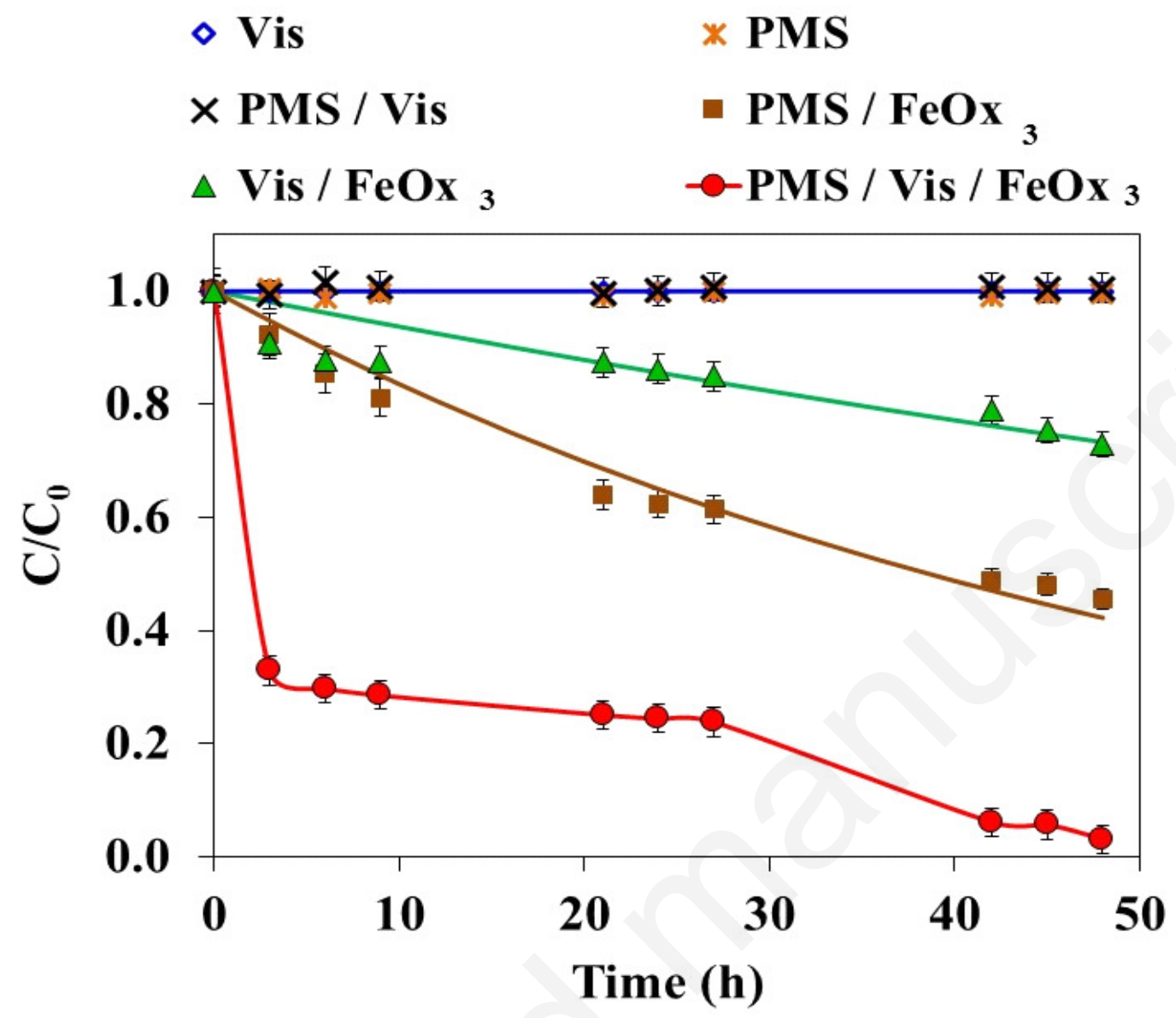

Figure 4. Comparison of different processes for FLU removal. Experimental conditions: $[\mathrm{FLU}]_{0}=5 \mu \mathrm{M},[\mathrm{PMS}]_{0}=0.5 \mathrm{mM},\left[\mathrm{FeOx}_{3}\right]=0.26 \mathrm{~g} \mathrm{~m}^{-2}$ on PES, reaction time $=48 \mathrm{~h}, \mathrm{pH}_{0}$ $=7.0 \pm 0.2, \mathrm{~V}=200 \mathrm{~mL}$, recirculation flow rate $=325 \mathrm{~mL} \mathrm{~min}^{-1}$. For $\mathrm{FeOx}_{3}$, the solid line is only a visual guide. FLU = flumequine, PMS = peroxymonosulfate, Vis = Visible light. 

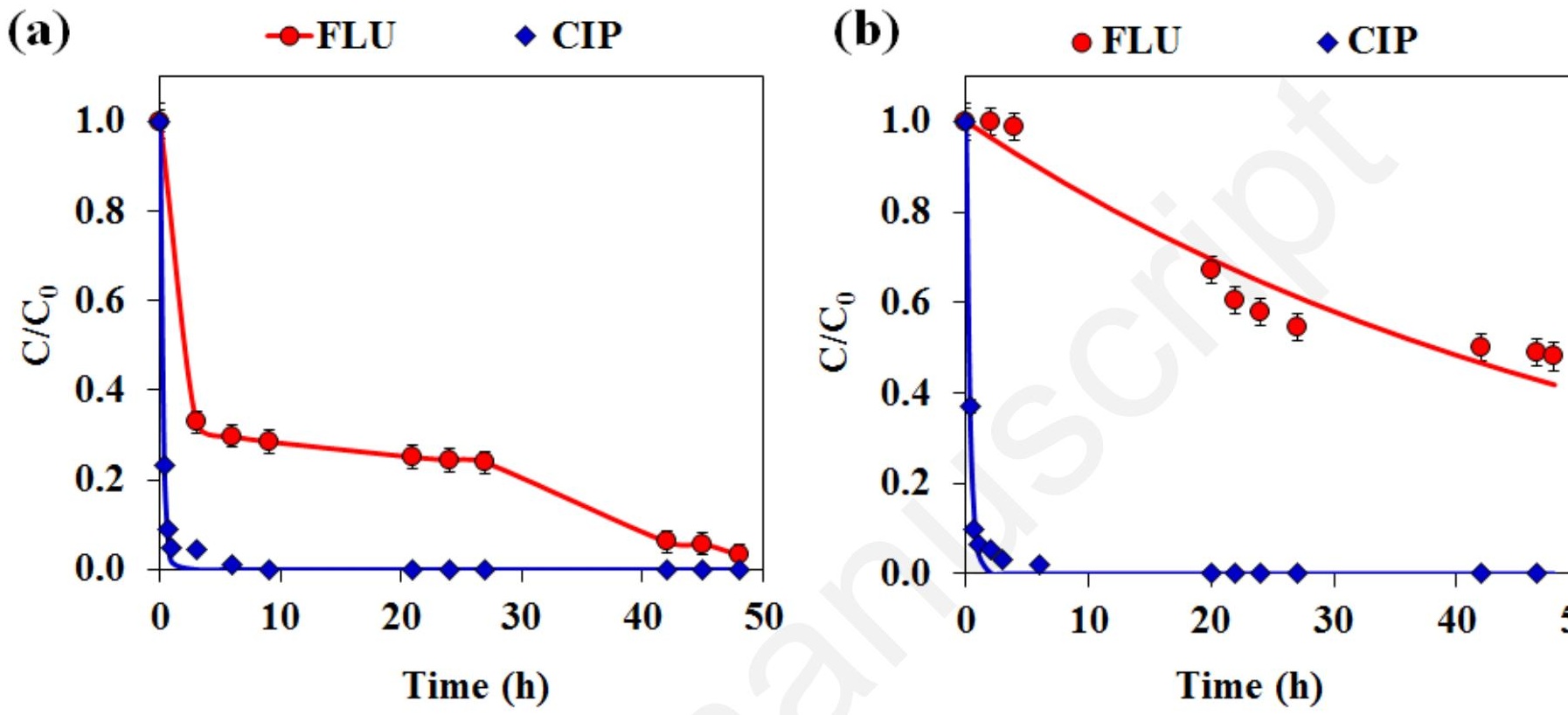

Figure 5. Removal kinetics of FLU and CIP in (a) single and (b) mixture system. Experimental conditions: Experimental conditions: $[\mathrm{FLU}]_{0}=[\mathrm{CIP}]_{0}=5 \mu \mathrm{M},[\mathrm{PMS}]_{0}=0.5$ $\mathrm{mM},\left[\mathrm{FeO}_{3}\right]=0.26 \mathrm{~g} \mathrm{~m}^{-2}$ on PES, visible reaction time $=48 \mathrm{~h}, \mathrm{pH}_{0}=7.0 \pm 0.2, \mathrm{~V}=200 \mathrm{~mL}$, recirculation flowrate $=325 \mathrm{~mL} \mathrm{~min}^{-1}$. For FLU in single system, the solid line is only a visual guide. Abbreviations: $F L U=$ flumequine,$C I P=$ ciproflo $x a c i n, \quad P M S=$ peroxymonosulfate. 

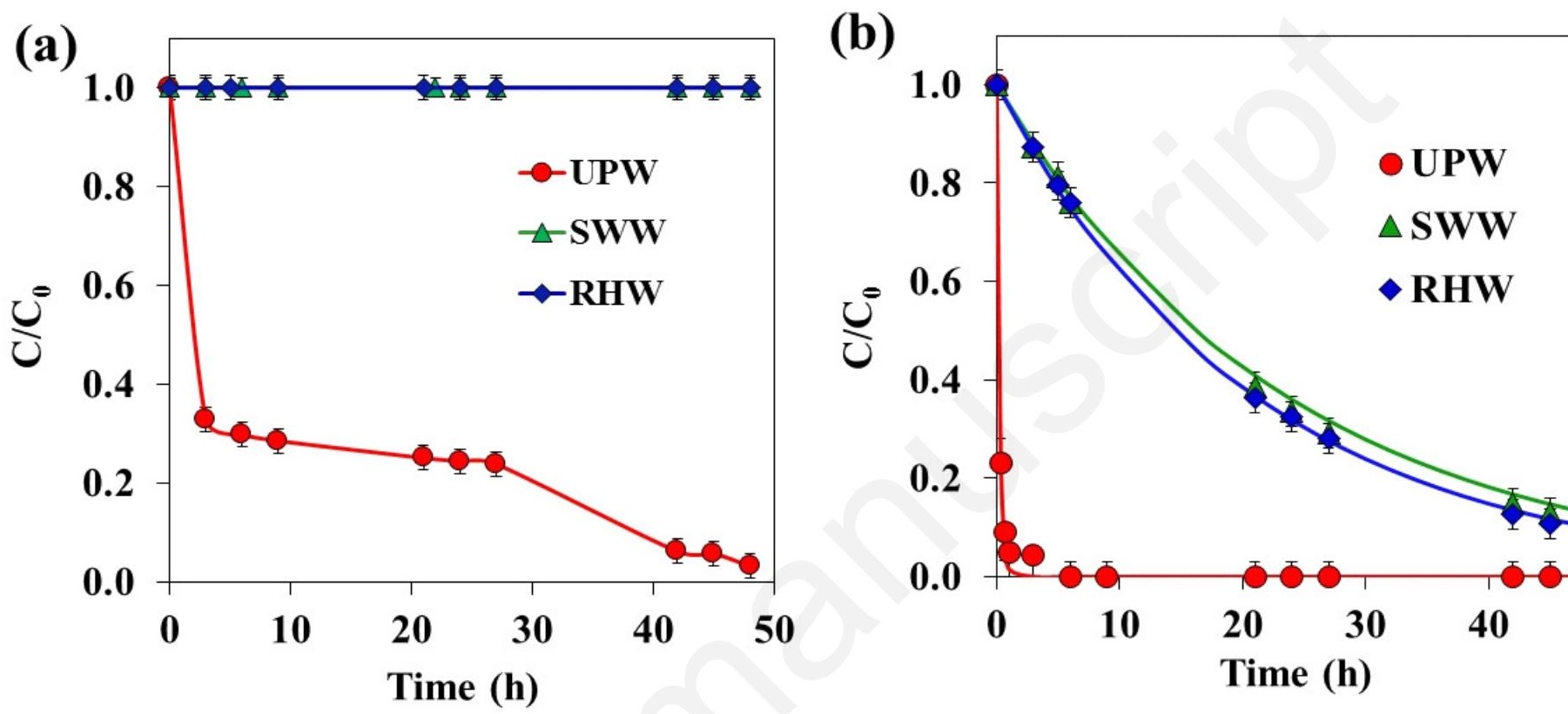

Figure 6. Effect of water matrix on (a) FLU and (b) CIP removal in single systems. Experimental conditions: $[\mathrm{FLU}]_{0}=[\mathrm{CIP}]_{0}=5 \mu \mathrm{M},[\mathrm{PMS}]_{0}=0.5 \mathrm{mM},\left[\mathrm{FeOx}_{3}\right]=0.26 \mathrm{~g} \mathrm{~m}^{-2}$ on PES, reaction time $=48 \mathrm{~h}, \mathrm{pH}_{0}=7.0 \pm 0.2, \mathrm{~V}=200 \mathrm{~mL}$, recirculation flowrate $=325 \mathrm{~mL}$ $\mathrm{min}^{-1}$. For FLU in UPW, the solid line is only a visual guide. Abbreviations: FLU = flumequine, CIP = ciprofloxacin, PMS = peroxymono sulfate, UPW = Ultra-pure water, SWW $=$ Synthetic wastewater, RHW $=$ Real hospital wastewater. 

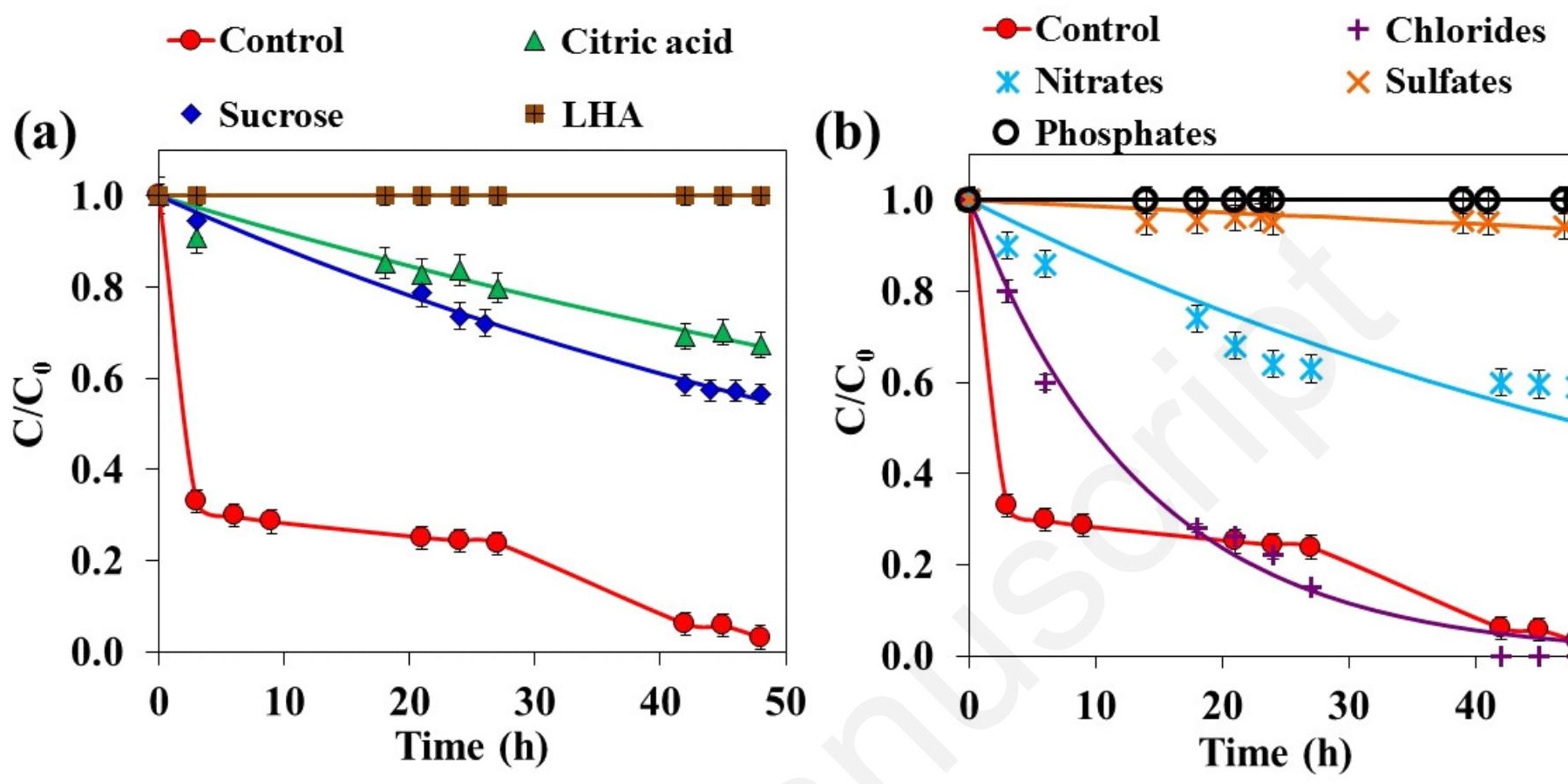

Figure 7. Effect of organic compounds (a) and inorganic anions (b) on FLU removal in UPW using $\mathrm{FeO}_{3}$-PES. Experimental conditions: : $[\mathrm{FLU}]_{0}=5 \mu \mathrm{M},[\mathrm{PMS}]_{0}=0.5 \mathrm{mM},\left[\mathrm{FeO}_{3}\right]=$ $0.26 \mathrm{~g} \mathrm{~m}^{-2}$ on PES, $\mathrm{pH}_{0}=7.0 \pm 0.2$, [Phosphate] $0=150 \mathrm{mg} \mathrm{L}^{-1}$, [Nitrate] $0=10 \mathrm{mg} \mathrm{L}^{-1}$, $[\text { Sulfate }]_{0}=120 \mathrm{mg} \mathrm{L}^{-1},[\text { Chloride }]_{0}=250 \mathrm{mg} \mathrm{L}^{-1},[\mathrm{LHA}]_{0}=40 \mathrm{mgC} \mathrm{L}^{-1},[\text { Citric acid }]_{0}=50$ $\mathrm{mg} \mathrm{L}^{-1}$, [Sucrose] $0=100 \mathrm{mg} \mathrm{L}^{-1}$, reaction time $=48 \mathrm{~h}, \mathrm{~V}=200 \mathrm{~mL}$, recirculation flow rate $=$ $325 \mathrm{~mL} \mathrm{~min}-1$. For the control test, the solid line is only a visual guide. Abbreviations: FLU = flumequine, $\mathrm{PMS}=$ peroxymonosulfate, $\mathrm{LHA}=$ Leonardite Humic Acid. 


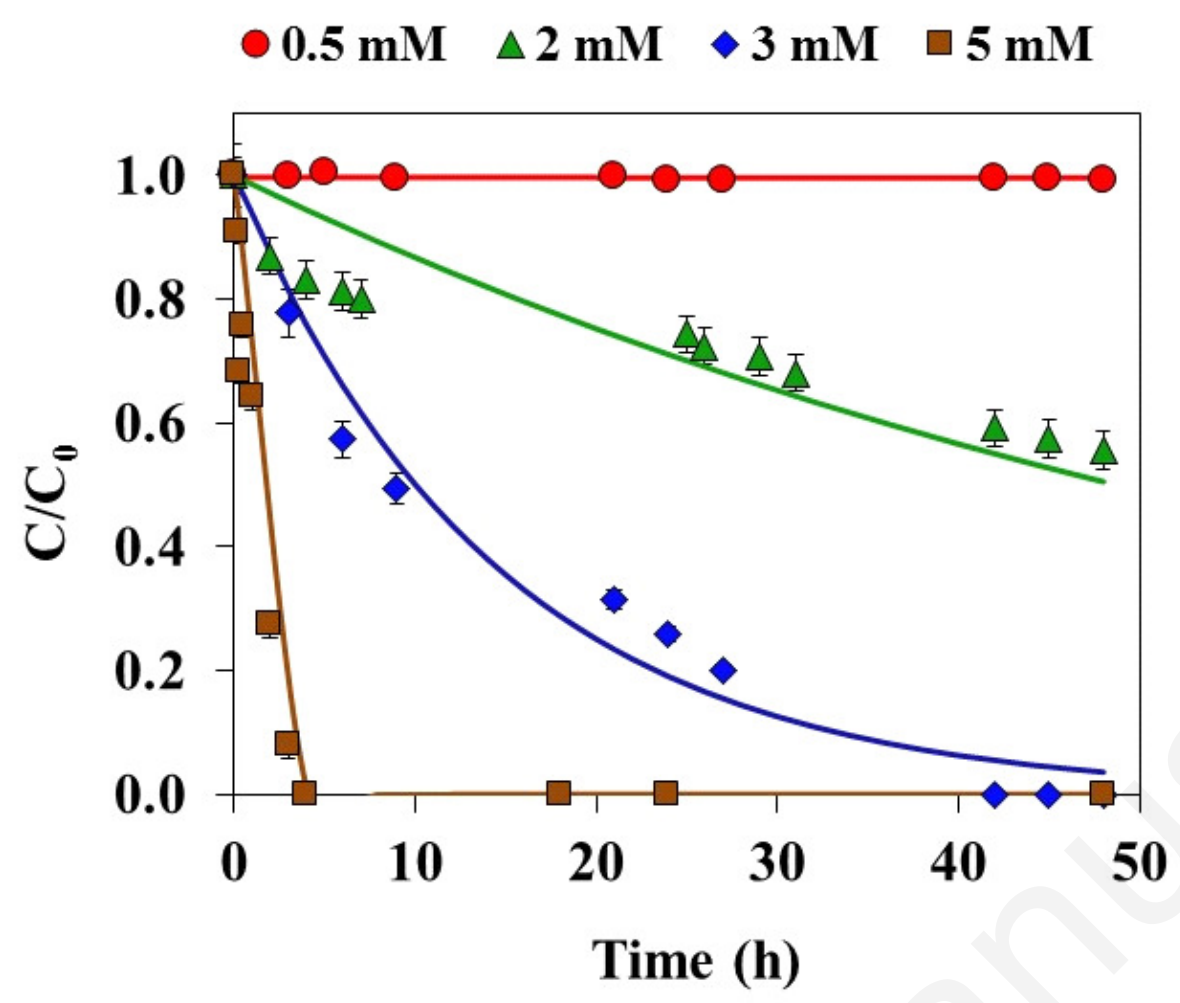

Figure 8. Effect of PMS concentration on FLU removal in RHW using FeOx3-PES. Experimental conditions: [FLU] $0=5 \mu \mathrm{M},\left[\mathrm{FeOx}_{3}\right]=0.26 \mathrm{~g} \mathrm{~m}^{-2}, \mathrm{pH}_{0}=7.0 \pm 0.2$, visible reaction time $=48 \mathrm{~h}, \mathrm{~V}=200 \mathrm{~mL}$, recirculation flow rate $=325 \mathrm{~mL} \mathrm{~min}^{-1}$. Abbreviations: $\mathrm{FLU}=$ flumequine, $\mathrm{PMS}=$ peroxymonosulfate, $\mathrm{RHW}=$ Real Hospital Wastewater, $\mathrm{FeO}_{3}$ corresponding to $3 \% \mathrm{O}_{2}$ in the sputtering chamber. 


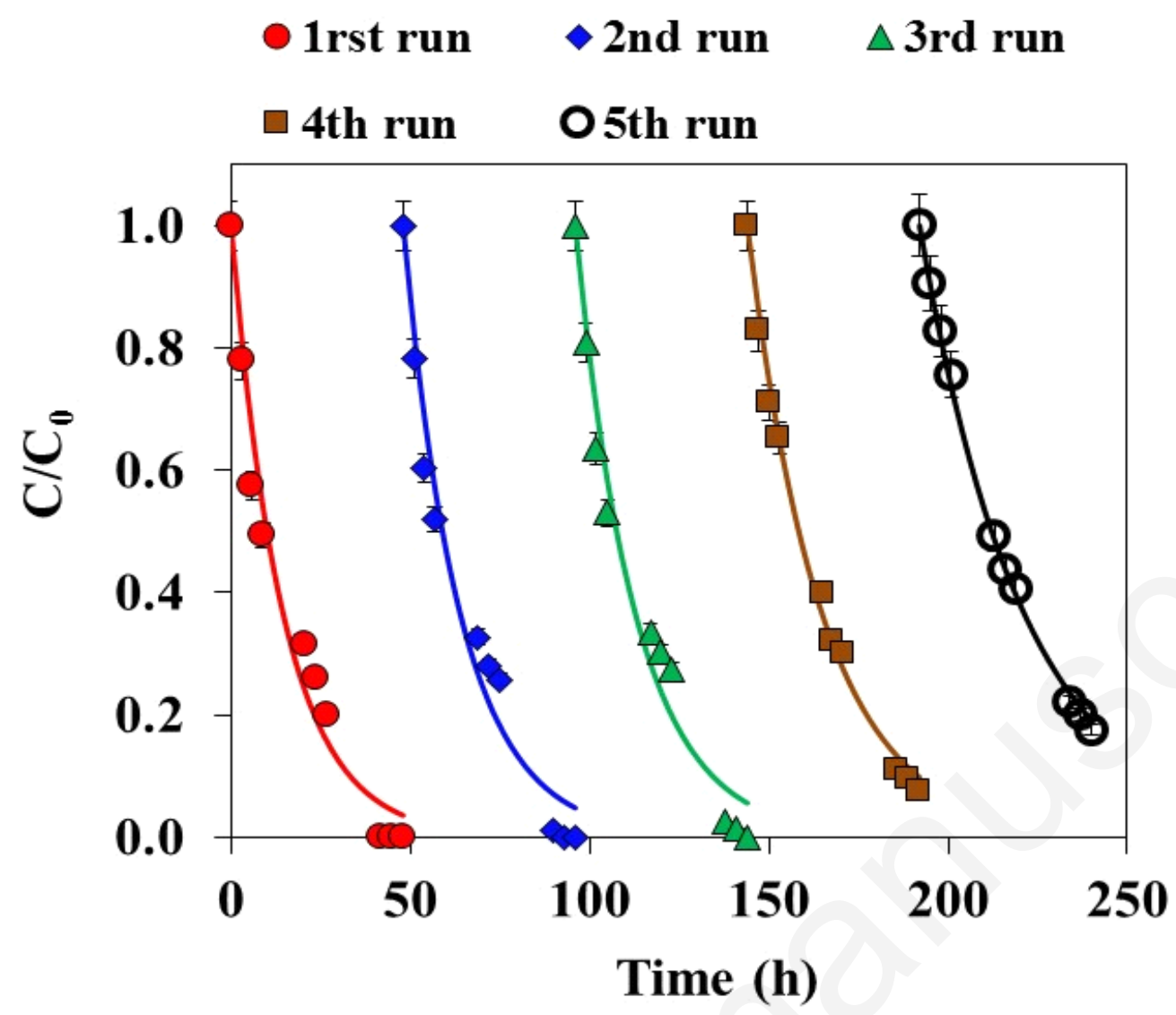

Figure 9. Removal kinetics of FLU in RHW over five successive runs. Experimental conditions: $[\mathrm{FLU}]_{0}=5 \mu \mathrm{M},[\mathrm{PMS}]_{0}=0.5 \mathrm{mM},\left[\mathrm{FeOx}_{3}\right]=0.26 \mathrm{~g} \mathrm{~m}^{-2}$ on PES, reaction time $=$ $48 \mathrm{~h}$, reaction time $=48 \mathrm{~h}, \mathrm{pH}_{0}=7.0 \pm 0.2, \mathrm{~V}=200 \mathrm{~mL}$, recirculation flow rate $=325 \mathrm{~mL}$ $\min ^{-1}$. Abbreviations: $\mathrm{FLU}=$ flumequine, $\mathrm{PMS}=$ peroxymonosulfate. 